Brazilian Journal

of Chemical

ISSN 0104-6632

Engineering

\title{
EFFECTS OF NANOPARTICLES AND SURFACTANT CHARGE GROUPS ON THE PROPERTIES OF VES GEL
}

\author{
G. Chauhan, K. Ojha* and A. Baruah \\ Indian Institute of Technology (Indian School of Mines), Dhanbad, Jharkhand, 826004, India. \\ E-mail:keka_ojha@yahoo.com \\ (Submitted: February 17, 2015 ; Revised: September 23, 2015 ; Accepted: November 1, 2015)
}

\begin{abstract}
Application of viscoelastic surfactant (VES) fluids in hydraulic fracturing is still in the development stage, though shear thinning behavior and water solubility are the two important characteristics behind increasing interest in their use in fracturing jobs. Effects of ionic characteristics and the concentration of different surfactants on the rheological properties of VES fluid have been investigated in detail in the present study for a number of surfactant systems. Phase behavior of the system was studied and the gel region was identified. Effects of alkali on the viscosity, thermal stability, and miscibility (in water) of the developed gel were also investigated. Dynamic rheological study was carried out to determine the storage modulus and loss modulus. This study shows that mixed anionic-anionic system gives improved rheology compared to single anionic and mixed anionic-zwitterionic surfactant systems.

Keywords: Hydraulic Fracturing; Viscoelastic gel; Surfactant based fluids; Rheology; Nanoparticles.
\end{abstract}

\section{INTRODUCTION}

Use of surfactants in various applications is almost as old as human civilization. They find wide application in industry because of their remarkable ability to influence the properties of surfaces and interfaces. Surfactants are applied at all stages in the petroleum recovery and processing units, starting from well drilling, hydraulic fracturing, EOR to other production operations. Surfactants generally form aggregates, i.e., micelles, where the hydrophobic tails form the core of the aggregate and the hydrophilic heads are in contact with the surrounding liquid when dissolved in an aqueous phase. Aggregates may be formed in different shapes: spherical or cylindrical micelles or lipid bilayers. The shape of the aggregates depends on the chemical structure of the surfactants, namely the balance in size between hydrophilic head and hydrophobic tail. Thus, variation in the head and tail groups will change the entire characteristics of the material formed with surfactants and other chemicals.

Use of viscoelastic surfactant based gels in fracturing fluids creates ordered structures, resulting in increased viscosity and elasticity without leaving any post fracture residue in the formation (Jennings, 1996; Armstrong et al., 1996). Fracturing fluid is injected at a rate and pressure greater than parting pressure of the rock to create the fractures (Samuel $e t$ al., 1997). To prevent the fracture face from closure because of flow back of fracturing fluid, proppants are incorporated in the fluids, which are left behind after the job, allowing conductive channels to remain open. Therefore, viscosity of the fluids is an important factor as it transports the proppant material into the fractures. "Premature Screenout", i.e., proppant drop out in the wellbore or fracture can happen because of low viscosity of the fracturing fluid (Kesavan and

*To whom correspondence should be addressed 
Homme, 2007). Use of Viscoelastic Surfactant based gels in fracturing fluids is a relatively new phenomenon, which uses surfactants in combination with inorganic salts or other surfactants to create ordered structures, resulting in increased viscosity and elasticity (Jennings, 1996; Armstrong et al., 1996). Viscoelastic surfactants are very small molecules with a molecular size 5,000 times smaller than guar molecules. They consist of a hydrophilic head group and a long hydrophobic tail (Yuan et al., 2012). They form elongated micellar aggregates in the presence of brine. Above a certain critical surfactant concentration, the micellar structures entangle and form a mesh-like structures. Depending on the size and shapes of the surfactants, ionic charges and the counter ions, ordered structures start to form, which increases viscosity and elasticity. The reverse mechanism is true for breaking these systems. The structures can be disrupted by adding an other surfactant, ionic additives and hydrocarbons from the formation, mutual solvents or other solvents or can be diluted by additional formation water as the surfactant concentration eventually falls to a level at which insufficient numbers of micelles are present to entangle and viscosity is lost (Dantas et al., 2006).

When micelles are disassociated by shear energy, the rheological behavior of VES fluids is similar to water, or nearly Newtonian; yet viscosity and elastic behavior recover when the disrupting energy is removed. VES requires less energy to pump than that required by conventional polymer fluids, effectively reducing wellsite pump-horsepower requirements (Nasr-El-Din et al., 2003; Khair et al., 2011).

Viscoelastic surfactant based gels can be obtained from microemulsified systems composed of aqueous phase, oil phase, surfactant and cosurfactant which are thermodynamically stable, iso-tropic and macroscopically homogenous dispersions of two immiscible fluids stabilized with either surfactant molecules alone or mixed with a cosurfactant (Yuan et al., 2012). Winsor's classification is used to study the phase diagram (Dantas et al., 2003a; Dantas et al., 2003b). The phase regions were obtained as Winsor I $(\mathrm{O} / \mathrm{W})$ : A microemulsion phase in equilibrium with an excess organic phase, Winsor II (W/O): A microemulsion phase in equilibrium with an excess aqueous phase, Winsor III (bicontinous or middle phase microemulsion): A three phase system where the microemulsion is in equilibrium with both excess organic and aqueous phases, and Winsor IV (homogeneous): a macroscopically homogenous system only consisting of a microemulsion phase (Dantas et al., 2003; Dantas et al., 2006; Mehta and Kaur, 2011;
Thampi et al., 2014). High viscoelastic properties with wormlike micellar growth have been reported in anionic and mixed-surfactant systems consisting of anionic-anionic, cationic-anionic and ionic-zwitterionic surfactants (Angelescu et al., 2003; Koehler et al., 2000; Tanford, 1972).

In some of our previous studies on designing of new surfactant-based hydraulic fracturing fluid, a microemulsion gel domain region was identified for an anionic surfactant (SDS) and isoamyl alcohol as cosurfactant at a cosurfactant-to-surfactant $(\mathrm{C} / \mathrm{S})$ ratio of 0.5 (Bajpai et al., 2010), and for sodium oleate as surfactant and two branched alcohols, 2-methyl butan-2-ol, 3-methyl butan-1-ol as cosurfactant (Thampi et al., 2014). The results of the rheological, proppant suspension and thermal study of the gel were found to be suitable for CBM, clay rock stimulation.

Also, in our previous study, a comparative rheological study on the VES-based gels prepared from single surfactant (anionic, SDS) and mixedsurfactant (zwitterionic,CAPB, and anionic, SDS) systems was performed to evaluate the performances of the different surfactant system gels (Baruah et al., 2014). In the present study, we report a rheological study on the mixed VES-based gels prepared from two anionic mixed surfactants (SDS and ALS) as a function of surfactant type, surfactant concentration, temperature, alkali concentration, and addition of nanoparticles and we have compared this with single surfactant SDS studies and anionic and zwitterionic SDS + CAPB by reference to our previous studies (Baruah et al., 2014).

\section{MATERIALS AND METHODS}

\section{Materials}

Sodium lauryl sulfate, with the common name sodium dodecyl sulfate (SDS), $\left[\mathrm{CH}_{3}\left(\mathrm{CH}_{2}\right)_{11} \mathrm{OSO}_{3} \mathrm{Na}\right]$, an anionic surfactant, was procured from LobaChemie Pvt. Ltd., Mumbai, India. Liquid anionic surfactant ammonium lauryl sulfate, with the common name ammonium dodecyl sulfate (ALS), $\left[\mathrm{C}_{12} \mathrm{H}_{29} \mathrm{NO}_{4} \mathrm{~S}\right]$, was obtained from Alpha Chemicals Pvt. Ltd., Navi Mumbai, India. Isoamyl alcohol (3-methylbutan-1-ol), used as cosurfactant, was purchased from Merck Specialties Pvt. Ltd., Mumbai, India. Pine oil was used as the organic phase. Samples were prepared using distilled water. Sodium hydroxide $(\mathrm{NaOH})$ of purity greater than $98 \%$ was obtained from LobaChemie Pvt. Ltd., Mumbai, India. Silicon di- 
oxide $\left(\mathrm{SiO}_{2}\right)$ nanoparticles with an average particles size of $15 \mathrm{~nm}$ and purity of $99.5 \%$ were obtained from SRL Pvt. Ltd., Mumbai, India. All chemicals used were of high purity and hence used as received. Methods

\section{Preparation of the Pseudo-Ternary Phase Diagram}

Determination of the gel region in the phase diagram is important to identify the appropriate composition for the gel with the most suitable properties. The pseudo-ternary phase diagram was constructed using a water titration method at fixed temperature $\left(25^{\circ} \pm 1 \mathrm{C}\right)$. For easy representation, the two constituents, namely, surfactant and cosurfactant are kept in a fixed proportion, forming a "pseudoconstituent". The phase diagram was plotted with a cosurfactant to surfactant $(\mathrm{C} / \mathrm{S})$ ratio of $1: 2$ by weight. This ratio can be varied for further studies. For the mixed surfactant system, the ratio of ALS to SLS was fixed at 1:2 by weight. The ratio of oil to the mixture of surfactant and cosurfactant was varied from 1:9 to $9: 1$ by weight. The preparation of the phase diagram and surfactant based gel were described in Baruah et al., 2014.

\section{Rheological Measurements}

Viscosities of gels were measured at variable shear rate and temperature. A Parr Physica US 200 rheometer (Anton Parr, Graz, Austria) with coneand-plate geometry $(50 \mathrm{~mm}$ cone diameter and a cone angle of $2^{\circ}$ ) maintained at a distance of $500 \mu \mathrm{m}$ was used for measuring the viscosities of samples. The test temperature was varied from 30 to $80{ }^{\circ} \mathrm{C}$ for VES samples. At constant set temperature, the shear rate was varied from 1 to $1000 \mathrm{~s}^{-1}$ for all the tests. A modular compact rheometer, MCR-302 (Anton Paar, Austria), was used for frequency sweep measurements and again cone-and-plate geometry maintained at a gap size of $500 \mu \mathrm{m}$ was used for testing VES samples. The cone (CP 50-1/Q1) had a diameter of $50 \mathrm{~mm}$ and a cone angle of $1^{\circ}$.

\section{Miscibility Tests}

To get an estimation of breaking characteristics of the prepared VES gel samples, miscibility tests were performed. Kinematic viscosity of the solution was determined using a Cannon Fenske viscometer with different orifice diameters as required $(25,50,150$, 200 , and $300 \mathrm{~mm}$ ). The test was carried out in presence of distilled water by mixing the gel with water at different proportions. The reduction in viscosity was reported as kinematic viscosity (centistokes, cSt), then converted to absolute viscosities (centipoises, cP). The gel-to-water ratio was fixed at 1:3, 1:2, 1:1, $2: 1$, and $3: 1$. The test temperatures were varied from 30 to $60{ }^{\circ} \mathrm{C}$.

\section{RESULTS AND DISCUSSION}

\section{Phase Studies of Quaternary Systems with (ALS + SDS) as Mixed Surfactant System}

The phase diagram of the quaternary system, with distilled water as the aqueous phase, iso-amyl alcohol as the co-surfactant and pine oil as the organic phase with the mixed surfactant system (ALS+SLS), is shown in Figure 1, at a cosurfactant to surfactant $(\mathrm{C} / \mathrm{S})$ ratio of 0.50 . A solid-liquid biphasic (SL) region exists, along with a semi-transparent solution at higher concentration of surfactant. A three-phase (3E) region exists near a water-rich region at lower surfactant concentration. In the $3 \mathrm{E}$ region, a milky emulsion phase lies in between a thin oil layer (above) and water phase (bottom). Also a milky emulsion with excess water, i.e., a two-phase (2E) region, exists. A milky liquid - single emulsion (1E) phase exists near the oil-rich corner. A microemulsion phase (WIV) exists, which is a transparent single isotropic liquid. The range of formation of a microemulsion zone depends on the physicochemical properties of the oil, aqueous phases, surfactant type, presence of a very low surface tension at the oil-water interface and high fluid interfacial film of surfactant and last, association and penetration of oil molecules in the interfacial surfactant film (Rajib and Bidyut, 2005; Hou, 1987). This area corresponds to an area of mutual solubility in both the systems consisting of mixed-surfactant/co-surfactant/pine oil/ water and it occurs in the water-rich domain. A clear and viscous microemulsion (GEL) region exists near this region. Also a viscous, white fluid (WV) region exists near this GEL region. This clear and viscous gel region is our area of interest for the preparation of viscoelastic surfactant based fracturing fluid.

For the accomplishment of the rheological study, two points were chosen in the gel region:

Point 1: 21.33 wt \% surfactant, where ALS is 7.11 and SLS is $14.22,10.6 \mathrm{wt} \%$ cosurfactant, 22.66 wt $\%$ oil, and $51 \mathrm{wt} \%$ water, i.e., $32 \% \mathrm{C} / \mathrm{S}$ at a constant water to oil ratio of $3: 1$.

Point 2: 22.66 wt \% surfactant, where ALS is 7.55 and SLS is $15.10,11.33 \mathrm{wt} \%$ cosurfactant, 
$22.66 \mathrm{wt} \%$ oil, and $51 \mathrm{wt} \%$ water, i.e., $34 \% \mathrm{C} / \mathrm{S}$ at a constant water to oil ratio of $3: 1$.

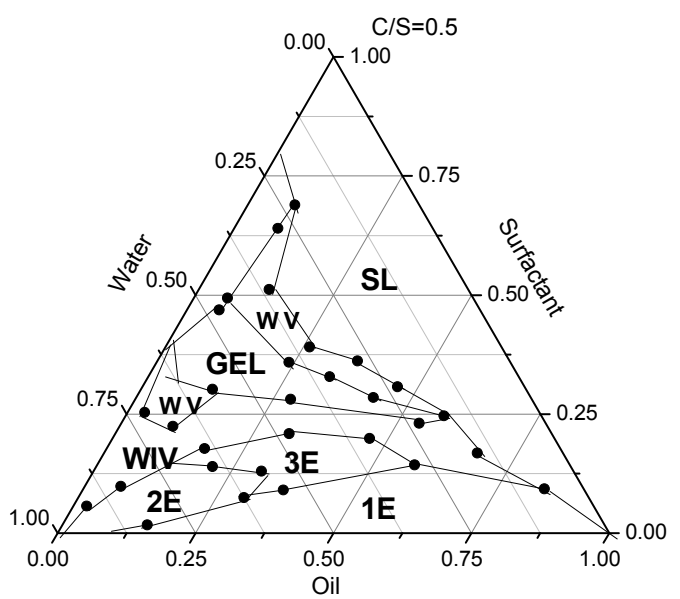

Figure 1: Pseudo-ternary phase diagram for Sodium Lauryl Sulfate+ Ammonium Lauryl Sulfate/isoamyl alcohol/pine oil/water system.

\section{Steady Shear Rheology of VES Gels}

Figures 2-5 present the values of viscosity for different surfactant (ALS+SLS) based viscoelastic gels at 32 and $34 \% \mathrm{C} / \mathrm{S}$ concentration with $0.05 \% \mathrm{NaOH}$ and $0.1 \% \mathrm{NaOH}$. Figures 2 and 3 present the effect of addition of $\mathrm{NaOH}$ on $34 \% \mathrm{C} / \mathrm{S}$ ALS+SLS at 30 and $80{ }^{\circ} \mathrm{C}$ respectively. For the shear rate range between 1 to $1000 \mathrm{~s}^{-1}, 34 \% \mathrm{C} / \mathrm{S}$ ALS+SLS with $0.1 \%$ $\mathrm{NaOH}$ always presented higher value of viscosity than $34 \% \mathrm{C} / \mathrm{S} \mathrm{ALS}+\mathrm{SLS}$ at 0.05 and $0 \% \mathrm{NaOH}$. Raising the $\mathrm{pH}$ of VES fluids by addition of alkali, i.e., sodium hydroxide (Figure 2 ) results in viscosity enhancement for any test temperature between 30 to $70{ }^{\circ} \mathrm{C}$. This is due to the fact that addition of $\mathrm{NaOH}$ (counter ions) to the solution decreases the electrostatic repulsive forces between surfactant molecules in a micelle and also decreases the spontaneous curvature of the aggregates, thus promoting micelle growth (Hoffmann et al., 1982; Pal 1998; Acharya, 2007). As a result, long, flexible anionic wormlike micelles with higher relaxation time and zero shear viscosity are formed in the solution, which resembles a polymer solution of high viscoelasticity (Thampi et al., 2014; Baruah et al., 2014).

Figure 4 presents the variation of viscosity with shear rate $\left(1-1000 \mathrm{~s}^{-1}\right)$ for $34 \% \mathrm{C} / \mathrm{S}(\mathrm{ALS}+\mathrm{SLS})$ with $0.1 \% \mathrm{NaOH}$ within the shear rate range of 1 to $1000 \mathrm{~s}^{-1}$ at temperatures of $30,60,70$ and $80{ }^{\circ} \mathrm{C}$. From the figure it is clear that the viscosity decreases with increase in temperature and shear rate up to $60{ }^{\circ} \mathrm{C}$ and beyond this temperature the viscosity increases. The former behavior is due to the fact that the aggre- gates formed move away from each other and a continuous decrease in viscosity is observed. At the temperatures beyond $60{ }^{\circ} \mathrm{C}$, viscosity increases because of increased surfactant-water interactions, and hence, more surfactant penetrates into the aqueous phase, increasing the micelle volume and resulting in increased viscosity (Dantas et al., 2003; Yang et al., 2015). But at increased temperature above $70{ }^{\circ} \mathrm{C}$ (Figure 3), addition of alkali forbids this enhanced surfactant-water interaction effect because addition of counter ions resulted in decreased electrostatic repulsion between surfactant molecules. Therefore, at $80{ }^{\circ} \mathrm{C}$ temperature, 34\% ALS+SLS with $0 \% \mathrm{NaOH}$ presented a higher value of viscosity than the VES fluids in the presence of alkali.

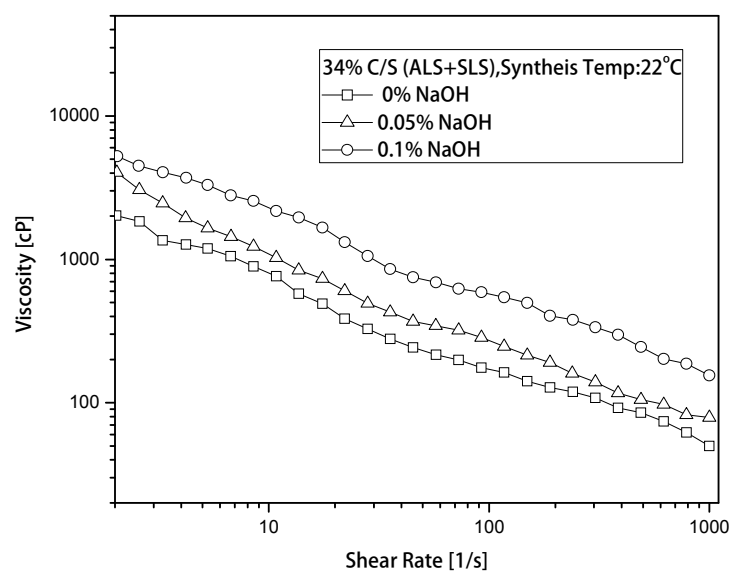

Figure 2: Effect of alkali $(\mathrm{NaOH})$ on $\mathrm{SBG}$ : $34 \% \mathrm{C} / \mathrm{S}$ $(\mathrm{ALS}+\mathrm{SLS})$ at $30^{\circ} \mathrm{C}$.

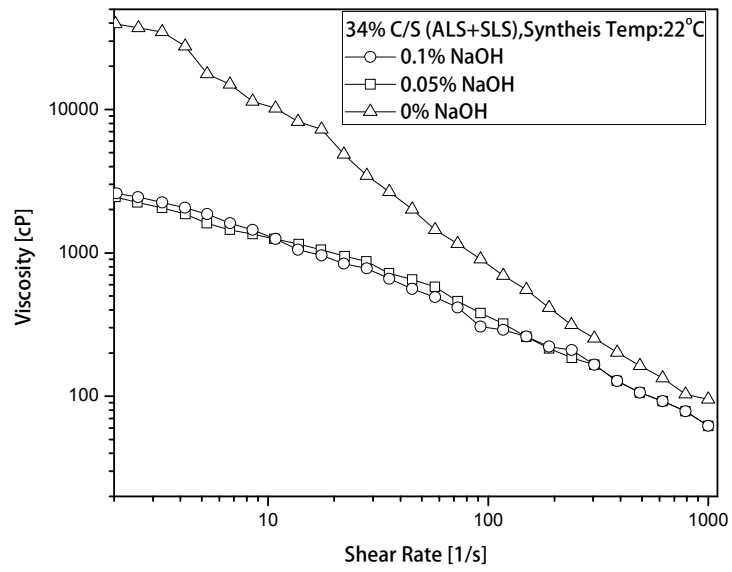

Figure 3: Effect of alkali $(\mathrm{NaOH})$ on $\mathrm{SBG} 34 \% \mathrm{C} / \mathrm{S}$ $(\mathrm{ALS}+\mathrm{SLS})$ at $80^{\circ} \mathrm{C}$.

Figure 5 shows the variation of viscosity for $32 \%$ and 34\% ALS+ SLS with concentration of $\mathrm{NaOH}$ varying from 0 to $0.1 \% \mathrm{NaOH}$. $34 \% \mathrm{C} / \mathrm{S}$ always presented a higher viscosity value at any test temperature between $30-60{ }^{\circ} \mathrm{C}$ and any shear rate than 


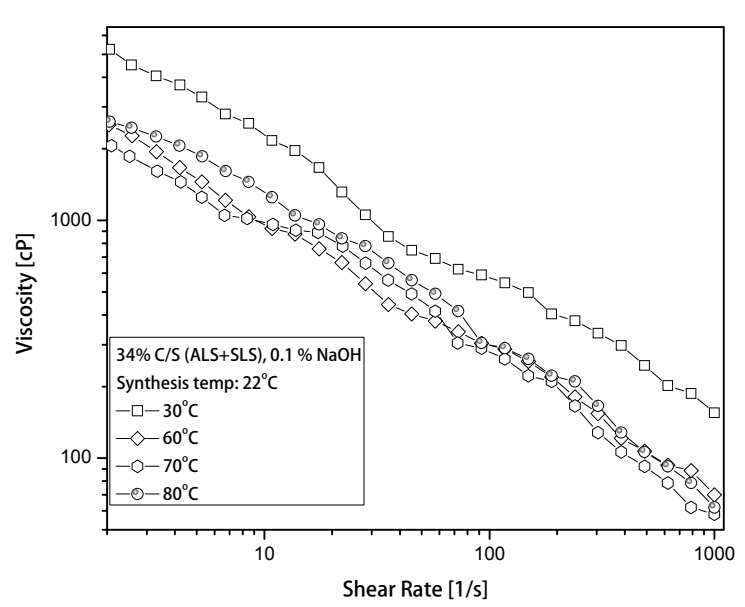

Figure 4: Variation of SBG i.e. 34\% C/S ALS+SLS with Shear Rate at different temperature for $0.1 \%$ $\mathrm{NaOH}$ concentration.

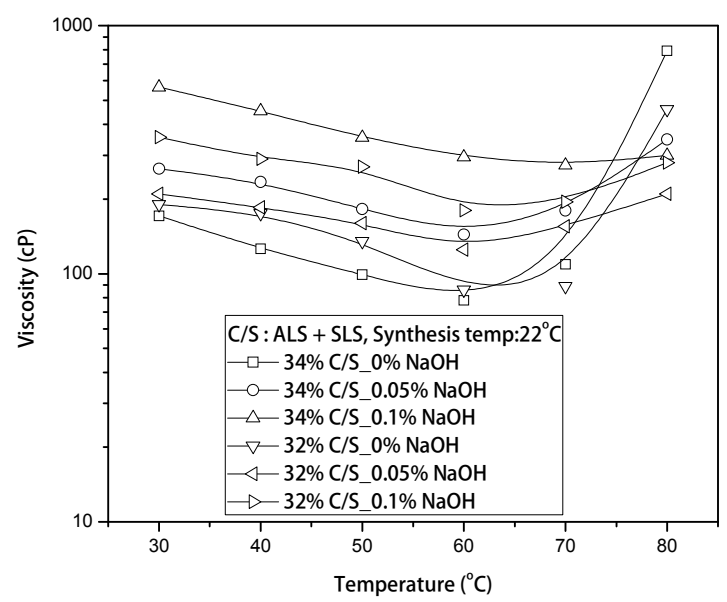

Figure 5: Comparison of SBG of 32\% and 34\% C/S ALS+SLS at $100 \mathrm{~s}^{-1}$ Shear Rate for $0 \%, 0.05 \%$ and $0.1 \% \mathrm{NaOH}$ concentrations.

$32 \% \mathrm{C} / \mathrm{S}$. This is because increased surfactant concentration enhances the growth and entanglement of worm-like micelles, i.e., Micellar Aggregation Number $(\mathrm{N})$ increases at higher surfactant concentration and $\mathrm{N}$ decreases with increase in temperature (Pal, 1998). It can be observed from Figures 2 to 5 that the apparent viscosity decreases with increasing shear rate for all temperatures, indicating the shear thinning nature of the fluids. The reduction in viscosity is due to breaking of a network of wormlike micelles as the micelles align themselves in the direction of shear, which occurs even in the presence of alkali at increased temperature. Yet viscosity and elastic behavior are recovered once the disrupting energy is removed. In particular, the molecular thermodynamic theory describes this ionic/ionic interaction and mi- cellar growth as it occurs due to the modification of the apparent surface per headgroup and screening of the electrostatic repulsion between the headgroups. The proper balance between the different contributions to the free energy of micellization can result in maximization of the aggregation number for particular compositions (Pal, 1998; Grillo, 2014).

The mixed surfactant system was selected so as to see the result of interaction of two anionic surfactant systems and their effect on the rheology as compared to single (anionic, SLS) and mixed (anionic, SLS and zwitterionic, CAPB) surfactant systems, which were studied earlier (Baruah et al., 2014). Though gel was formed in increased surfactant concentration of $32 \%$ for $3: 1$ water oil ratio in case of mixed anionic-anionic surfactant system but thermal stability was found to be increased by $10{ }^{\circ} \mathrm{C}$ from the single surfactant system. Table 1 presents viscosity values at $100 \mathrm{~s}^{-1}$ shear rate for $32 \%$ $\mathrm{C} / \mathrm{S} \mathrm{SLS}, 30 \% \mathrm{C} / \mathrm{S}(\mathrm{SLS}+\mathrm{CAPB})$ and for $32 \% \mathrm{C} / \mathrm{S}$ (ALS+SLS). Several laboratory studies and field experiences with polymeric fluids led to the development of an important guideline that the fluid should have a viscosity of $100 \mathrm{cP}$ at $100 \mathrm{~s}^{-1}$ for adequate proppant transport as this shear rate value also represents the field condition of pumping the fracturing fluid down the wellbore (Zana and Kaler, 2007). This leads to the selection of a constant shear rate value of $100 \mathrm{~s}^{-1}$. Viscosity of $32 \% \mathrm{C} / \mathrm{S}(\mathrm{ALS}+\mathrm{SLS})$ is greater than single SLS surfactant system $(32 \% \mathrm{C} / \mathrm{S}$ SLS) but lower than mixed anionic-zwitterionic $30 \% \mathrm{C} / \mathrm{S}(\mathrm{SLS}+\mathrm{CAPB})$ surfactant system. Though viscosity is lower than the anionic-zwitterionic surfactant system, but the present anionic-anionic system is more cost effective and readily available surfactants in the markets than zwitterionic surfactants. Viscosity is increased due to increase in charge density. The anionic-anionic mixed surfactant system is more surface active than single SLS or ALS systems. The two surfactant systems have a different rheological behavior, even though they are very similar in their chemical composition. The differences here are due to the distribution of charge on the cylindrical micelles (Hoffman, 1994). Also, the viscosity of this anionic-anionic mixed surfactant system is less than that of the anionic-zwitterionic mixed surfactant system, as the effect of electrostatic attraction of the hydrophilic part between the cationic portion of the zwitterionic and the anionic portion of the dodecyl sulfate ion is higher than the charge density effect of the anionic-anionic mixed surfactant system. 
Table 1: Viscosity (cP) values at $100 \mathrm{~s}^{-1}$ shear rate for $32 \% \mathrm{C} / \mathrm{S} \mathrm{SLS,} 30 \% \mathrm{C} / \mathrm{S}$ (SLS+CAPB) and for $32 \% \mathrm{C} / \mathrm{S}$ (ALS+SLS) with reference from Baruah et al. (2014).

\begin{tabular}{|c|c|c|c|c|c|c|}
\hline \multirow{2}{*}{ Temp, ${ }^{\circ} \mathrm{C}$} & \multicolumn{2}{|c|}{$32 \% \mathrm{C} / \mathrm{S}$ SLS } & \multicolumn{2}{|c|}{$30 \% \mathrm{C} / \mathrm{S}(\mathrm{CAPB}+\mathrm{SLS})$} & \multicolumn{2}{|c|}{$32 \% \mathrm{C} / \mathrm{S}(\mathrm{ALS}+\mathrm{SLS})$} \\
\hline & $0 \% \mathrm{NaOH}$ & $0.1 \% \mathrm{NaOH}$ & $0 \% \mathrm{NaOH}$ & $0.1 \% \mathrm{NaOH}$ & $0 \% \mathrm{NaOH}$ & $0.1 \% \mathrm{NaOH}$ \\
\hline 30 & 142 & 290 & 240 & 360 & 190 & 355 \\
\hline 40 & 60 & 240 & 190 & 310 & 170 & 290 \\
\hline 50 & 48 & 190 & 140 & 275 & 110 & 270 \\
\hline 60 & 35 & 160 & 110 & 220 & 90 & 180 \\
\hline
\end{tabular}

\section{Effect of addition of Nanoparticles}

In VES fluids, nanotechnology application is used for maintaining viscosity at high temperatures and controlling fluid loss without damaging the formation. For this study, $500 \mathrm{ppm}$ inorganic silicon dioxide $\left(\mathrm{SiO}_{2}\right)$ nanoparticles were selected, which displayed unique surface morphology and reactivity. Viscosity is the measure of a fluid's resistance to gradual deformation by tensile or shear stress. More resistance to viscosity loss with an increase in temperature is a qualitative analysis of thermal stability which had been used as a parameter for thermal stability by many authors like Crews and Huang (2008), Tamas et al. (2014), Baruah et al. (2014) etc. 34\% $\mathrm{C} / \mathrm{S}$ (ALS+SLS) with $0.1 \% \mathrm{NaOH}$ and $500 \mathrm{ppm} \mathrm{SiO}_{2}$ nanoparticles exhibited higher resistance to high temperatures and shear rate by maintaining a higher value of viscosity; thus, they can be considered to be more thermally stable than $34 \% \mathrm{C} / \mathrm{S}(\mathrm{ALS}+\mathrm{SLS})+$ $0.1 \% \mathrm{NaOH}$ without nanoparticles. These nanometerscale particles react with VES micelles by chemisorptions and surface charge attraction to stabilize fluid viscosity at high temperatures and produce a pseudofilter cake of viscous VES fluid that significantly reduces the fluid loss rate. In other words, a high density 3D-network of worm-like micelles is obtained, which makes the micelles more thermally resistant to higher temperature (Crews and Huang, 2008). The increase in thermal stability by addition of $\mathrm{SiO}_{2}$ nanoparticles can be observed in Figure 6 . When nanoparticles are added to the VES solution, they will associate or create intramicellar "pseudocrosslinking", giving a much stronger dynamic micelle network (Huang and Crews, 2008). Also, addition of nanoparticles leads to the formation of micelle-particle junctions that effectively join two or more micelles (Crews and Huang, 2008).

The temperature increase leads to microdrop mobility intensification, which influences the activation energy of the system. This viscosity-temperature relationship can be explained by Arrhenius type equations applied to the cumulative effect described by the shear stress (Tamas et al., 2014).

$$
\eta=A \cdot e^{\frac{E a}{R T}}
$$

where $E_{a}$ is the viscous flow activation energy ( $\mathrm{J}$ $\left.\mathrm{mol}^{-1}\right) ; R$ is the universal gas constant, having a value

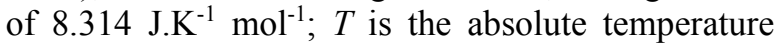
and $A$ represents a material constant ( $\mathrm{Pa} \mathrm{s}$ ) (Hassan et al., 1998).

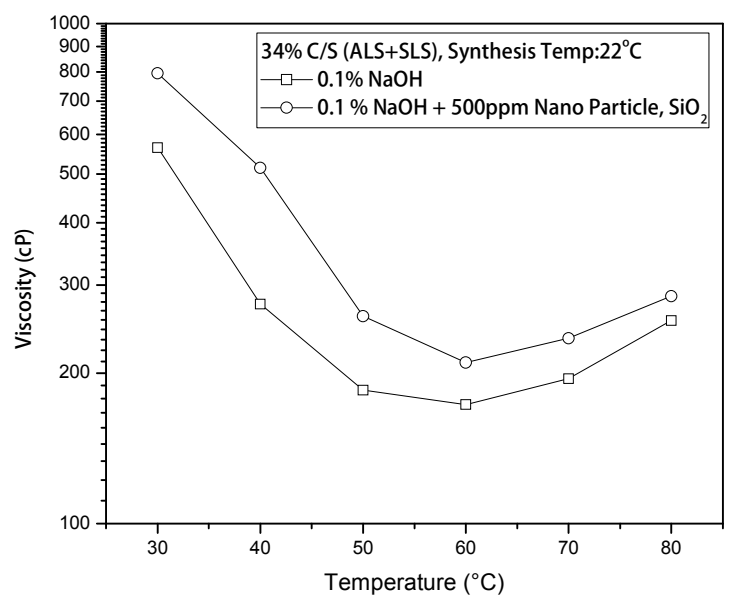

Figure 6: Effect of addition of $500 \mathrm{ppm} \mathrm{SiO}_{2}$ nanoparticles to $34 \% \mathrm{C} / \mathrm{S}$ ALS+SLS with $0.1 \% \mathrm{NaOH}$ for different temperatures at $100 \mathrm{~s}^{-1}$ shear rate.

Figure 7 shows the plot of the logarithm of the viscosity versus the reciprocal of the temperature for $34 \% \mathrm{C} / \mathrm{S}$ ALS+SLS, $0.1 \% \mathrm{NaOH}$ with $0 \mathrm{ppm}$ and $500 \mathrm{ppm}$ nanoparticles for test temperatures between $30-60{ }^{\circ} \mathrm{C}$. A near linear plot was obtained for $34 \%$ $\mathrm{C} / \mathrm{S}$ ALS+SLS, $0.1 \% \mathrm{NaOH}+500 \mathrm{ppm}$ nanoparticles $\left(\mathrm{R}^{2}=0.9605\right.$ with standard error of 0.150$)$, which is in good agreement with the Arrhenius type equation, while the plot for $34 \% \mathrm{C} / \mathrm{S}$ ALS+SLS, $0.1 \% \mathrm{NaOH}$ shows some deviation from linearity $\left(\mathrm{R}^{2}=0.8932\right.$ with standard error of 0.217$)$. However, it was used for the estimation of activation energy values, as no other established correlation is available in the literature. All of the relevant statistical information for constructing a linear regression equation is presented in Table 2. 
Table 3 gives the ANOVA results for linear plots for both the gels. The significance value of 0.020 $(<0.05)$ for $34 \%$ ALS+SLS+ $0.1 \% \mathrm{NaOH}$ with 500 ppm $\mathrm{SiO}_{2}$ nanoparticles supports the linear relationship between $\ln \eta$ and $(1 / \mathrm{T})$, while the significance value of $0.055(>0.05)$ for $34 \%$ ALS + SLS $+0.1 \%$ $\mathrm{NaOH}$ means there is some deviation from a linear relationship.

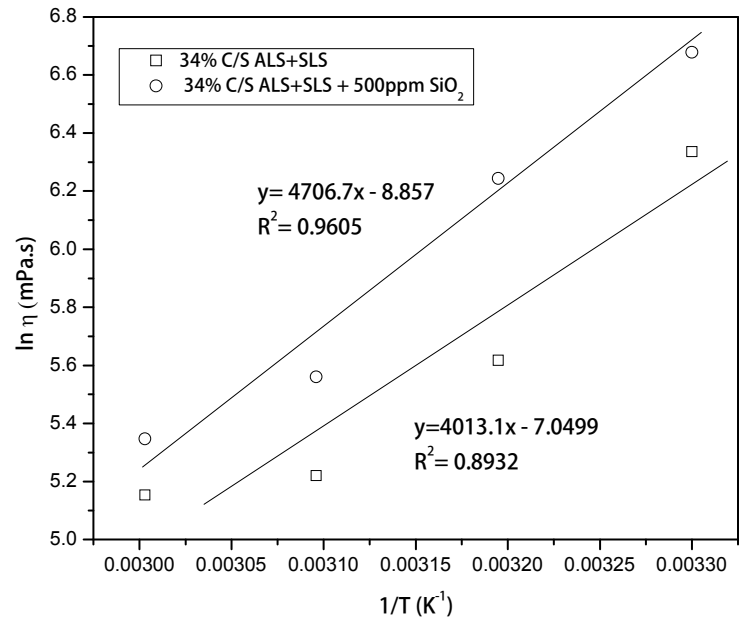

Figure 7: Plot of $\ln \eta$ vs $1 / \mathrm{T}$ for $34 \% \mathrm{C} / \mathrm{S}$ ALS+SLS and $34 \% \mathrm{C} / \mathrm{S}$ ALS+SLS $+500 \mathrm{ppm} \mathrm{SiO}_{2}$ at $0.1 \%$ $\mathrm{NaOH}$ for $303-330 \mathrm{~K}$ temperature range.

Table 2: Table for Coefficients of Arrhenius linear plot with their standard error and significance value for $34 \% \mathrm{C} / \mathrm{S} \mathrm{ALS}+\mathrm{SLS}+0.1 \% \mathrm{NaOH}$ with 0 and $500 \mathrm{ppm} \mathrm{SiO}_{2}$.

\begin{tabular}{|l|r|r|c|}
\hline \multirow{3}{*}{ 34\% C/S } & \multicolumn{2}{|c|}{$\begin{array}{c}\text { Unstandardized } \\
\text { Coefficients }\end{array}$} & \multirow{2}{*}{ Significance } \\
\cline { 2 - 3 } & \multicolumn{1}{|c|}{ B } & \multicolumn{1}{|c|}{ Std. Error } & \\
\hline For 0 ppm SiO & & & \\
Slope & & & \\
Intercept & 4013.143 & 981.004 & 0.055 \\
\hline For 500 ppm SiO & -7.050 & 3.090 & 0.150 \\
Slope & & & \\
Intercept & 4706.724 & 675.213 & 0.020 \\
\hline
\end{tabular}

Table 3: ANOVA table for linear plots for $34 \%$ $\mathrm{C} / \mathrm{S}$ ALS+SLS+0.1\% $\mathrm{NaOH}$ with 0 and $500 \mathrm{ppm}$ $\mathrm{SiO}_{2}$.

\begin{tabular}{|l|c|c|c|c|}
\hline $\begin{array}{c}\mathbf{3 4 \%} \mathbf{C} / \mathbf{S} \\
\text { ALS+SLS+0.1\% NaOH }\end{array}$ & $\begin{array}{c}\text { Sum of } \\
\text { Squares }\end{array}$ & $\begin{array}{c}\text { Degree of } \\
\text { Freedom }\end{array}$ & $\begin{array}{c}\text { Mean } \\
\text { Square }\end{array}$ & $\begin{array}{c}\text { Significan } \\
\text { ce }\end{array}$ \\
\hline 1. For 0 ppm SiO & & & & \\
Regression & 0.790 & 1 & 0.790 & 0.055 \\
Residual & 0.094 & 2 & 0.047 & \\
$\quad$ Total & 0.885 & 3 & & \\
\hline 2. For 500 ppm SiO & & & & \\
Regression & 1.087 & 1 & 1.087 & 0.020 \\
Residua & 0.045 & 2 & 0.022 & \\
Total & 1.132 & 3 & & \\
\hline
\end{tabular}

Values of the activation energy were calculated using the slope value $\left[\mathrm{E}_{\mathrm{a}} / \mathrm{RT}\right]$ of the linear plot, as shown in Figure 7 and results are tabulated in Table 4. The mean value and standard deviation of the activation energies for both the samples are presented in Table 4, which showed that the nanoparticle-induced mixed surfactant system had a higher value of the activation energy $(39.131 \mathrm{~kJ} / \mathrm{mol})$ compared to the surfactant system without nanoparticles $(33.365$ $\mathrm{kJ} / \mathrm{mol}$ ). This high value points to higher thermal stability of nanofluids and the presence of a 3-D network of micelles involving stronger interactions between macromolecular aggregates than are present in other fluids (Dantas et al., 2003b).

Table 4: Activation energy values for different samples in the temperature range of 303-333K.

\begin{tabular}{|c|l|c|c|}
\hline S.No & \multicolumn{1}{|c|}{ Sample } & $\begin{array}{c}\text { Mean Value of the } \\
\text { Activation Energy, } \\
\text { E (kJ/mol) }\end{array}$ & $\begin{array}{c}\text { Std. } \\
\text { Deviation }\end{array}$ \\
\hline 2 & $\begin{array}{l}34 \% \mathrm{C} / \mathrm{S} \mathrm{ALS}+\mathrm{SLS}, 0.1 \% \\
\mathrm{NaOH}\end{array}$ & 33.365 & 0.471 \\
\hline 4 & $\begin{array}{l}34 \% \mathrm{C} / \mathrm{S} \text { ALS+SLS, 0.1\% } \\
\mathrm{NaOH}+500 \text { ppm nano } \\
\text { particle }\end{array}$ & 39.131 & 0.327 \\
\hline
\end{tabular}

\section{Shear Stress vs. Shear Rate}

Figure 8 shows the variation of the shear stress ( $\tau$, $\mathrm{Pa})$ as a function of the shear rate $\left(\gamma, \mathrm{s}^{-1}\right)$ for $34 \%$ $\mathrm{C} / \mathrm{S}$ ALS+SLS with 0 ppm and $500 \mathrm{ppm} \mathrm{SiO}_{2}$ nanoparticles. The fluid is basically a non-Newtonian fluid and the shape of the flow curves is represented by a power-law equation:

$\tau=k \gamma^{n}$

where " $k$ " is the consistency index (in $\mathrm{N} \cdot \mathrm{s} / \mathrm{m}^{2}$ ), and " $n$ " is the dimensionless flow behavior index. This equation is also called the Ostwald-de Waele relationship (Goel et al., 2002). Table 5 shows the mean values and standard deviation values of the power law parameters calculated manually using the shear stress and shear rate data for $34 \% \mathrm{C} / \mathrm{S}$ ALS+SLS $+0.1 \% \mathrm{NaOH}$ with $0 \%$ and 500 ppm $\mathrm{SiO}_{2}$ nanoparticles. It can be seen that all " $n$ " values are less than 1 , representing a pseudoplastic nature and the plots of shear rate vs. shear stress are concave downward, which also represents a pseudoplastic behavior, i.e., shear thinning nature. A near power law plot was obtained for $34 \% \mathrm{C} / \mathrm{S}$ ALS+SLS, $0.1 \% \mathrm{NaOH}+500$ ppm nanoparticle $\left(\mathrm{R}^{2}=0.9553\right.$ with standard error of 0.257), while the plot for $34 \% \mathrm{C} / \mathrm{S}$ ALS+SLS, $0.1 \%$ $\mathrm{NaOH}$ shows a certain deviation from the power law model $\left(\mathrm{R}^{2}=0.837\right.$ with standard error of 0.400$)$. The coefficient values with their standard error of estimate are presented in Table 6 . 


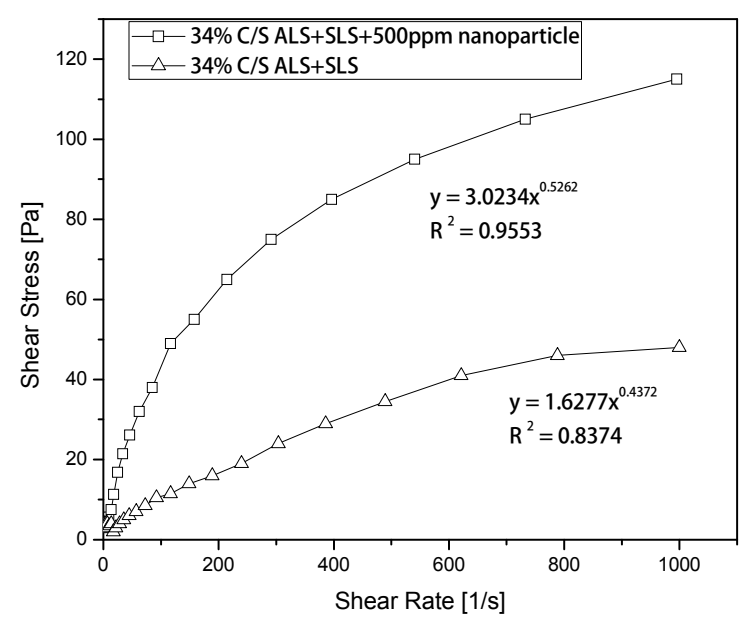

Figure 8: Variation of shear stress vs. shear rate for $34 \%$ SLS+ALS with and without nanoparticles.

To test the difference between theoretical and experimental power law parameters, the t-test was performed and the results are tabulated in Table 7. The Levene test for ' $k$ ' and ' $n$ ' was performed to determine the quality variances and significance values. It can be observed from the table that the significance value is equal to 0.000 which is less than $p=0.05$, i.e., the assumption of equality of variances for the ttest is violated. Therefore, "Equal variances not assumed" t-statistics is considered in the Table 7. Since the significance values of the power law parameters " $\mathrm{n}$ " and " $\mathrm{k}$ " for both the samples are greater than $0.05\left[0.360\left(\mathrm{n}_{1}\right), 0.620\left(\mathrm{k}_{1}\right), 0.681\left(\mathrm{n}_{2}\right)\right.$ and $\left.0.146\left(\mathrm{k}_{2}\right)\right]$, the power law model is validated by all the experimental data.

\section{Dynamic Oscillatory Measurements}

Dynamic Oscillatory experiments measure the linear viscoelastic response of materials and are known to be the most valuable probes of gel or network structure. Steady shear measurements accurately represent the process conditions and oscillatory measurements are necessary for an insight into the numbers of network crosslinks. Linear Viscoelastic measurements can be used to determine the crosslink density of the gel, the kinetics of gel formation and shear degradation of the gel structure (Goel et al., 2002).

Table 5: Values of $k$ and $n$ for different SBG.

\begin{tabular}{|c|l|c|c|c|c|c|c|}
\hline S.No & \multirow{2}{*}{ Sample } & \multicolumn{2}{|c|}{ Value of flow behavior index, $\mathbf{n}$} & \multicolumn{3}{|c|}{ Value of consistency index, $\mathbf{k}$} \\
\cline { 3 - 7 } & & Mean value & Std. deviation & $\begin{array}{c}\text { Theoretical } \\
\text { value }\end{array}$ & Mean value & $\begin{array}{c}\text { Std. deviation } \\
\text { Theoretical } \\
\text { value }\end{array}$ \\
\hline 1. & $34 \% \mathrm{C} / \mathrm{S} \mathrm{ALS}+\mathrm{SLS}$ & 0.508 & 0.346 & 0.437 & 1.965 & 3.062 & 1.627 \\
2. & $34 \% \mathrm{C} / \mathrm{S} \mathrm{ALS}+\mathrm{SLS}+500 \mathrm{ppm} \mathrm{SiO} 2$ & 0.490 & 0.414 & 0.526 & 4.237 & 3.858 & 3.023 \\
\hline
\end{tabular}

Table 6: Coefficient table with standard error and significance value for $34 \%$ C/S ALS+SLS+0.1\% NaOH with 0 and $500 \mathrm{ppm} \mathrm{SiO}_{2}$.

\begin{tabular}{|c|c|c|c|}
\hline \multirow{2}{*}{$34 \% \mathrm{C} / \mathrm{S}$ ALS+SLS+0.1\% NaOH } & \multicolumn{2}{|c|}{ Unstandardized Coefficients } & \multirow[t]{2}{*}{ Significance } \\
\hline & $\mathbf{B}$ & Std. Error & \\
\hline $\begin{array}{c}\text { For } 0 \text { ppm } \mathrm{SiO}_{2} \\
\mathrm{n}_{1} \\
\mathrm{k}_{1}\end{array}$ & $\begin{array}{l}0.437 \\
1.628\end{array}$ & $\begin{array}{l}0.036 \\
0.236\end{array}$ & $\begin{array}{l}0.000 \\
0.000\end{array}$ \\
\hline $\begin{array}{c}\text { For } \mathbf{5 0 0} \mathbf{~ p p m ~} \mathbf{S i O}_{2} \\
\mathrm{n}_{2} \\
\mathrm{k}_{2} \\
\end{array}$ & $\begin{array}{l}0.526 \\
3.023 \\
\end{array}$ & $\begin{array}{l}0.040 \\
0.490\end{array}$ & $\begin{array}{l}0.000 \\
0.000\end{array}$ \\
\hline
\end{tabular}

Table 7: Independent t-test for Power law parameters of 34\% C/S ALS+SLS +0.1\% NaOH with 0 and 500 ppm $\mathrm{SiO}_{2}$ nanoparticles.

\begin{tabular}{|c|c|c|c|c|c|}
\hline \multirow[b]{2}{*}{ Sample } & \multirow[b]{2}{*}{ Parameter } & & \multirow{2}{*}{$\begin{array}{c}\text { Levene's Test for Equality of } \\
\text { Variances } \\
\text { Significance }\end{array}$} & \multicolumn{2}{|c|}{ t-test for Equality of Means } \\
\hline & & & & $\begin{array}{l}\text { Degree of } \\
\text { freedom }\end{array}$ & $\begin{array}{c}\text { Significance } \\
\text { (2-tailed) }\end{array}$ \\
\hline \multirow{2}{*}{$\begin{array}{l}34 \% \mathrm{C} / \mathrm{S} \text { ALS }+\mathrm{SLS}+0.1 \% \\
\mathrm{NaOH}\end{array}$} & $\mathrm{n}_{1}$ & $\begin{array}{l}\text { Equal Variances Assumed } \\
\text { Equal Variances not Assumed }\end{array}$ & 0.000 & $\begin{array}{c}47 \\
20.000\end{array}$ & $\begin{array}{l}0.283 \\
0.360\end{array}$ \\
\hline & $\mathrm{k}_{1}$ & $\begin{array}{l}\text { Equal Variances Assumed } \\
\text { Equal Variances not Assumed }\end{array}$ & 0.000 & $\begin{array}{c}47 \\
20.000\end{array}$ & $\begin{array}{l}0.562 \\
0.620 \\
\end{array}$ \\
\hline \multirow{2}{*}{$\begin{array}{l}34 \% \mathrm{C} / \mathrm{S} \text { ALS }+\mathrm{SLS}+0.1 \% \\
\mathrm{NaOH}+500 \mathrm{ppm} \mathrm{SiO}_{2}\end{array}$} & $\mathrm{n}_{2}$ & $\begin{array}{l}\text { Equal Variances Assumed } \\
\text { Equal Variances not Assumed }\end{array}$ & 0.000 & $\begin{array}{l}47 \\
20\end{array}$ & $\begin{array}{l}0.660 \\
0.681 \\
\end{array}$ \\
\hline & $\mathrm{k}_{2}$ & $\begin{array}{l}\text { Equal Variances Assumed } \\
\text { Equal Variances not Assumed }\end{array}$ & 0.000 & $\begin{array}{c}47 \\
20.000\end{array}$ & $\begin{array}{l}0.115 \\
0.146 \\
\end{array}$ \\
\hline
\end{tabular}


Figures 9-10 show the variation of the storage modulus $\left[\mathrm{G}^{\prime}(\omega)\right]$ and loss modulus $\left[\mathrm{G}^{\prime \prime}(\omega)\right]$ with respect to frequency from 1 to $100 \mathrm{~s}^{-1}$ at $40{ }^{\circ} \mathrm{C}$. Oscillatory shear measurements were made for $34 \% \mathrm{C} / \mathrm{S}$ ALS+SLS system, and for the effect of addition of nanoparticles on the same.

For all samples, the storage modulus, $G^{\prime}(\omega)$, and the loss modulus, $G^{\prime \prime}(\omega)$, were almost independent of the angular frequency range since the curves are almost parallel to the $\mathrm{x}$-axis, which show basically the gel nature. The storage modulus always maintained a higher value than the loss modulus, indicating the viscoelastic nature of the fluid where elasticity is dominant.

The nanoparticle-induced mixed surfactant system exhibited higher values of $G^{\prime}(\omega)$ and $G^{\prime \prime}(\omega)$ as compared to the gel without nanoparticles. The presence of nanoparticles leads to stronger interactions between the macromolecular aggregates and a 3-D network of worm-like micelles is formed in the fluid.

The frequency where $G^{\prime}(\omega)=G^{\prime \prime}(\omega)$ (crossover point) is referred to as the relaxation time of the network. In both the samples, no crossover of $G^{\prime}(\omega)$ and $G^{\prime \prime}(\omega)$ was observed within the frequency range under investigation $\left(1-100 \mathrm{~s}^{-1}\right)$. This means that the crossover point must have been below $1 \mathrm{~s}^{-1}$, indicating good capacity of the fluid to suspend the particles, because the lower the crossover frequency, the higher the particle suspension capability (Gaillard et al., 2013). Also, recent studies have shown that fluids having a minimum viscosity value of $25 \mathrm{cP}\left(\right.$ at $\left.100 \mathrm{~s}^{-1}\right)$ and elastic modulus of $2 \mathrm{~Pa}$ are good enough to suspend proppant for hydraulic fracturing (Thampi et al., 2014). In the present case, both the samples had an elastic modulus value much higher than $2 \mathrm{~Pa}$ and viscosities above $100 \mathrm{cP}$.

\section{Miscibility Test}

The breaking characteristic of fracturing fluid was examined by carrying out miscibility tests for VES fluids in the presence of water. The viscosity of gel-water mixtures at different proportions is presented in Figures 10 and 11 as a function of temperature. The results show that the highly viscous gel is completely miscible with water and breaks into a low viscous liquid. This occurs as the worm-like micelles break into non-viscous, more spherical micelles, which can no longer form a network (Nasr-El-Din et al., 2003). Also by adding water to the gel, the surfactant concentration eventually falls to a level at which insufficient numbers of micelles are present to entangle and the viscosity decreases. Higher viscosity values were obtained at 2:1 and 3:1 ratios, which indicate that the gel is broken to a lesser extent, but presented a low viscosity at increased temperature. The nanoparticle-induced mixtures also behave similarly. These results clearly indicate that VES fluid does not need any breaker for cleaning of the formation after fracturing.

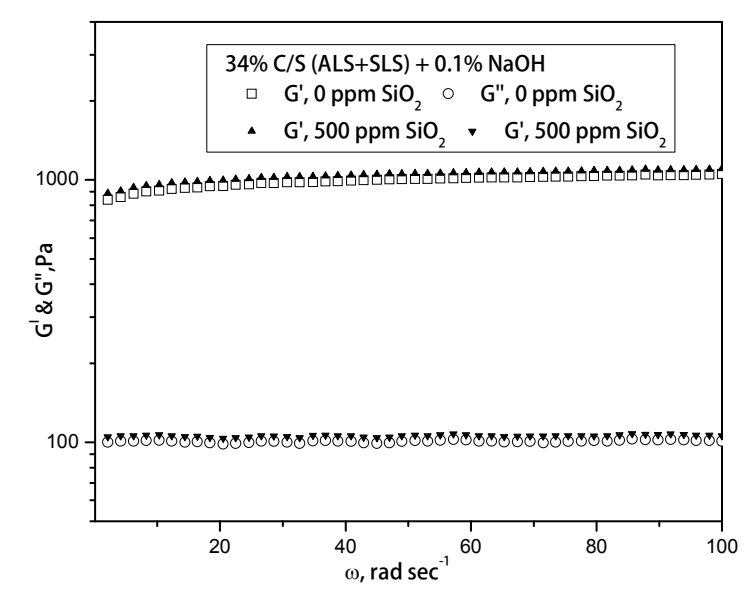

Figure 9: Variation of the storage $\left(G^{\prime}\right)$ and loss $\left(G^{\prime \prime}\right)$ moduli with frequency $(\omega)$ for $34 \% \mathrm{C} / \mathrm{S}$ ALS+SLS $+0.1 \% \mathrm{NaOH}$ for $0 \mathrm{ppm}$ and $500 \mathrm{ppm} \mathrm{SiO}_{2}$ nanoparticles at $40{ }^{\circ} \mathrm{C}$. 


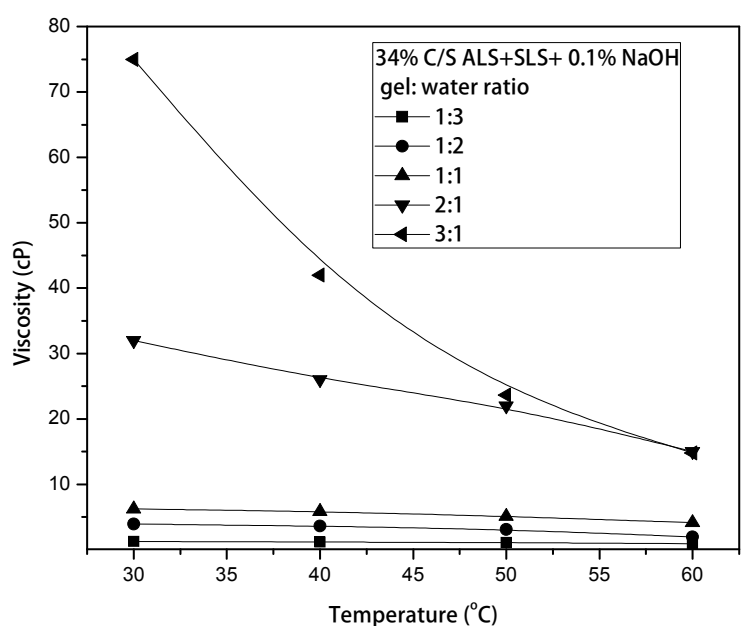

Figure 10: Variation of the viscosity with temperature for different gel - water ratios for $34 \% \mathrm{C} / \mathrm{S}$ ALS + SLS $+0.1 \% \mathrm{NaOH}$.

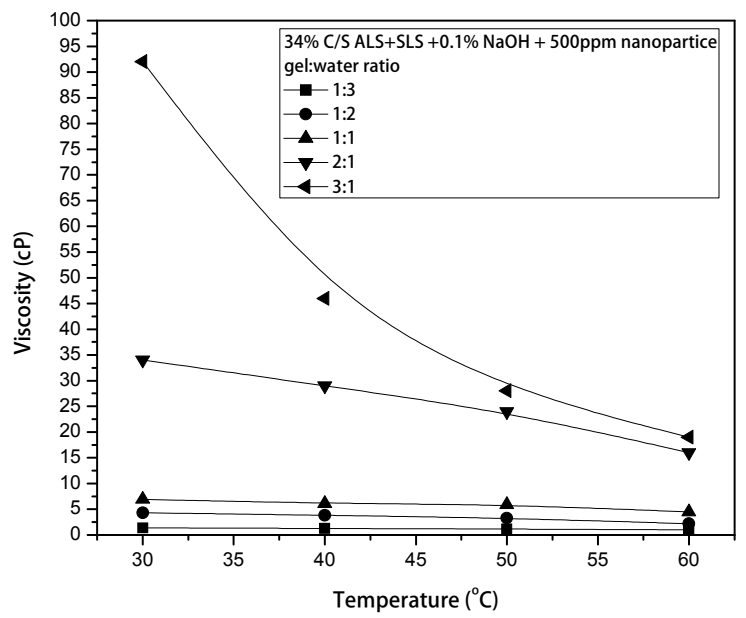

Figure 11: Variation of the viscosity with temperature for different gel -water ratios for $34 \% \mathrm{C} / \mathrm{S}$ ALS+SLS+0.1\% NaOH +500 ppm $\mathrm{SiO}_{2}$ nanoparticles.

\section{CONCLUSIONS}

In the present work, surfactant-based gels (VES) were synthesized with anionic surfactants, i.e., ammonium lauryl sulfate (ALS) and sodium lauryl sulfate (SLS). The rheology of the prepared gels shows shear thinning behavior with a prominent viscoelastic nature. Elasticity is predominant, which helps the proppant carrying capacity. Addition of $\mathrm{NaOH}$ improves the viscosity of the gel to a certain extent because of an increase in the micelle population in the basic medium. It could also be concluded from the results that a mixture of ALS and SLS provides a better gel system with higher viscosity compared to the individual surfactants. The VES gel also shows good miscibility in all proportions with water, thus nullifying the probability of formation of damage without the aid of any breaker. This prepared gel is thermally stable up to $70{ }^{\circ} \mathrm{C}$ and can be effectively used to fracture low temperature reservoirs like CBM.

\section{ACKNOWLEDGMENTS}

The authors thank the Council of Scientific and Industrial Research, India, for financial assistant [CSIR Project 22 (0625)/13/EMR-II] and the Department of Petroleum Engineering, Indian School of Mines, Dhanbad, India.

\section{REFERENCES}

Acharya, D., Varade, D. and Aramaki, K., Effect of temperature on the rheology of wormlike micelles in a mixed surfactant system. Journal of Colloid and Interface Science, 315-330-336 (2007).

Angelescu, D., Khan, A. and Caldararu, H., Viscoelastic properties of sodium dodecyl sulfate with aluminum salt in aqueous solution. Langmuir, 19(22), 9155-9161 (2003).

Armstrong, K., Roger, C., Navarette, R. and Nelson, E., Advanced fracturing fluids improve well economics. Oil field Review, 7, 43 (1996).

Bajpai, P., Singh, J. P., Mandal, A. and Ojha, K., The synthesis and characterization of a clean hydrofracturing fluid. J. Pet. Sci. Technol., 28(17), 17501760 (2010).

Baruah, A., Chauhan, G., Ojha, K. and Pathak, A., Phase behavior and thermodynamic and rheological properties of single- (SDS) and mixedsurfactant (SDS + CAPB)-based fluids with 3methylbutan-1-ol as the cosurfactant and pine oil as the organic phase. Industrial Engineering and Chemical Research, 53(51), 19765-19774 (2014). DOI: 10.1021/ie500987y

Carter, K. E., Hakala, A., Hammack, R. W., Hydraulic fracturing and organic compounds-uses. Disposal and Challenges. SPE 165692 (2013).

Crews, J. B. and Huang, T., Performance enhancement of viscoelastic surfactant stimulation fluids with nanoparticles. SPE 113533 (2008).

Dantas, T., Santanna, V., Neto, A., Maria, C. P., Moura, A. and Fonseca, J., Ethlyl and isoamyl alcohols as cosurfactants in gel systems. materials and interfaces. American Chemical Society, 42, 5809-5812 (2003a). 
Dantas, T., Santanna, V. C., Dantas Neto, A. A., Barros Neto, E. L. and Alencar Moura, M. C. P., Rheological properties of a new surfactant-based fracturing gel. Colloids and Surfaces, A, Physicochem. Eng. Aspects, 225, 129-135 (2003b).

Dantas, T. N. C., Santanna, V. C., Neto, A. A. D., Curbelo, F. D. S., Garnica, A. I. C., Methodology to break test for surfactant-basedfracturing gel. J. Pet. Sci. Eng., 50(34), 293-298 (2006).

Gaillard, N., Thomas, A., Favero, C., Novel associative acrylamide-based polymers for proppant transport in hydraulic fracturing fluids. SPE 164072 (2013). DOI 10.2118/164072-MS

Goel, N., Shah, S. N., Grady, B. P., Correlating viscoelastic measurements of fracturing fluid to particles suspension and solids transport. J. Pet. Sci. Eng., 35(1-2), 59-81 (2002).

Grillo, I. and Penfold, J., Self-assembly of mixed anionic and nonionic surfactants in aqueous solution. Langmuir, 27(12), 7453-7463 (2011). DOI: 10.1021/la200874g

Hassan, P. A., Candau, S. J., Kern, F., Manohar, C., Rheology ofwormlike micelles with varying hydrophobicity of the counter ion. Langmuir, 14(21), 6025-6029 (1998).

Hoffmann, H., Platz, G., Rehage, H., Schorr, W., The influence of the salt concentration on the aggregation behavior of viscoelastic detergents. Adv. Colloid Interface Sci., 17(1), 275-298 (1982).

Hoffman, H., Viscoelastic Surfactant Solutions. Chapter 1, p. 10, ACS Symposium Series (1994).

Hou, M., Hou, J. and Shah, D., Effect of the molecular structure of the interface and continuous phase on solubilzation of water in water/oil microemuslions. Langmuir, 3, 1086-1096 (1987). DOI 10.1021/1a00078a036

Huang, T. and Crews, J. B., Nanotechnology applications in viscoelastic-surfactant stimulation fluids. SPE Prod. Oper, 23(4), 512-517, SPE 107728 (2008).

Jennings, A., fracturing fluids - then and now. SPE 36166 (1996).

Kesavan, S., Homme, R., Rheology of guar and HPG crosslinked by Borate. Macromolecules, 25, 20262032 (1992).

Khair, E. M. M., Shicheng, Z., Shanbo, M., Mei, Z., Performance and application of new anionic D3FAS05 viscoelastic fracturing fluid. J. Pet. Sci. Eng., 78(1), 131-138 (2011). DOI: 10.1016/j.petrol. 2011.05.011
Koehler, R. D., Raghavan, S. R., Kaler, E. W., Microstructure and dynamics of wormlike micellar solutions formed by mixing cationic and anionic surfactants. J. Phys. Chem., B, 104(47), 1103511044 (2000).

Mehta, S. and Kaur, G., Microemulsions: Thermodynamic and Dynamic Properties. Department of Chemistry and Centre of Advanced Studies in Chemistry, Prof. Mizutani Tadashi (Ed.), InTech (2011).

Nasr-El-Din, H. A., Samuel, E., Samuel, M., Application of a newclass of surfactant in stimulation treatments. SPE 84898 (2003). DOI: 10.2118/84898 -MS

Pal, R., Rheology of drag-reducing surfactant solutions. ASME, 245, 155-130 (1998).

Prud'homme, R. K., Chu, A. and Kramer, J., Rheological Characterization of Fracturing Fluids. Princeton University (1984).

Rajib, K. M., Bidyut, K. P., Physicochemical investigations of microemulsification of eucalyptus oil and water using mixed surfactants (AOT + Brij35 ) and butanol. J. Colloid Interface Sci., 283(2), 565-577 (2005).

Samuel, M., Card, R. J., Nelson, E. B., Brown, E., Vinod, P. S., Polymer-free fluid for hydraulic fracturing. SPE, 38622 (1997).

Tanford, C., Micelle Shape and Size. Journal of Physical Chemistry, 76(21), 1078 (1972). DOI: 10.1021/j100665a018

Tamas, A., Vincze, M. and Padure, M., Rheological properties of some surfactant-based fracturing fluids. Int. Journal of Engineering Research and Applications, 4(2), 95-101 (2014).

Thampi, N., Ojha, K., Nair, U., Effect of branched alcohols on phase behavior and physicochemical properties of Winsor IV microemulsions. J. Surfact Deterg., 17, 371381 (2014).

Yuan, Z., Qin, M., Chen, X., Liu, C., Li, H., Hao, J., Phase behavior, rheological property, and transmutation of vesicles in fluorocarbon and hydrocarbon surfactant mixtures. Langmuir, 28(25), 9355-9364(2012).

Yang, J., Cui, W., Lu, Y., Guan, B., Qiu, X., Liu, P., Instant gel formation of viscoelastic surfactant fracturing fluids by diluting through lamellar liquid crystal. Journal of Petroleum Science and Engineering, 125 (2015) 90-94 (2015).

Zana, R., Kaler, E. W., Giant Micelles: Properties and Applications. CRC Press (2007). 